\title{
Trends and Disparities in Quality of Diabetes Care in the US: The National Health and Nutrition Examination Survey, 1999-2016
}

Shweta Kamat, MS; Yolene Gousse, DrPH; Jagannath Muzumdar, PhD; Anna Gu MD, PhD

St. John's University, Queens, NY

\begin{abstract}
Objectives: To examine trends and disparities in the quality of diabetes care among US adults with diabetes. Methods: Individuals aged 20 years or older with diabetes from NHANES (1999-2016) were included in the study. Quality indicators for diabetes care included Hemoglobin A1c (HbA1c) < 8\%, Blood Pressure (BP) $<130 / 80 \mathrm{~mm} \mathrm{Hg}$, Low-Density Lipoprotein (LDL-C) < $100 \mathrm{mg} / \mathrm{dL}$, triglycerides $<150$ $\mathrm{mg} / \mathrm{d}$, receiving eye and foot examinations in the past year, and meeting with a diabetes educator in the past year. Results: $A$ total of 7,521 adults with diabetes were identified. During the 18-year study period, significant improvements in diabetes care were observed in the overall study sample. Adjusted regression analyses showed that compared with their White counterparts, Blacks were more likely to have received eye $(O R=1.37 ; P=0.01)$ and foot $(O R=1.42 ; P=0.01)$ examinations and met a diabetes educator $(O R=1.40 ; P<0.01)$ over the past year. However, Blacks were significantly less likely to achieve treatment goals for $H b A 1 c(O R=0.77, P=0.02), B P(O R=0.75$, $P<0.01), L D L-C(O R=0.68, P<0.01)$. Hispanics in general had suboptimal healthcare utilization for diabetes but the Hispanic-white disparities in diabetes care outcomes were attenuated after controlling for patient sociodemographic, clinical and utilization characteristics. Overall, suboptimal quality of diabetes care were particularly prominent among adults without health insurance and those with lower educational attainment. Conclusions: In the United States, despite persistent efforts, racial disparities in quality of diabetes care still persist. Lack of health insurance and lower socioeconomic status are among the strongest predictors of poor quality of diabetes care. These findings provide valuable information in developing policies and practices to promote racial equity in diabetes care.
\end{abstract}

Keywords: diabetes, race and ethnicity, epidemiology, quality and outcomes

\section{Introduction}

Diabetes mellitus (diabetes) is one of the most prevalent chronic disorders in the United States (US). Based on National Diabetes Statistics Report of 2017, 30.2 million (12.2\%) US adults have diabetes (1). It is a leading risk factor for atherosclerotic cardiovascular disease (ASCVD), heart failure, and microvascular complications. At present, diabetes is the seventh leading cause of death in the US and the rates of the disease have been steadily increasing over the past two decades $(2,3)$. Over time, uncontrolled diabetes can lead to kidney failure and diseases of the lower limbs and feet. Given that there is no cure for diabetes, prevention and disease management are the two key approaches to lessening the morbidity and mortality associated with diabetes.

The control of risk factors for diabetes care has improved but considerable gaps prevail between guideline recommendations and quality of care in the U.S. $(2,3)$, especially among certain patient groups. Clinical guidelines have been established for diabetes management and control of its risk factors to increase life expectancy (4). More specifically the guidelines emphasize

Corresponding author: Anna Gu, MD PhD

Department of Pharmacy Administration and Public Health

St. John's University

8000 Utopia Parkway, Queens, NY 11439

Phone: 718-990-8263; Fax: 718-990-6316

Email: gus@stjohns.edu on the management of atherosclerotic disease to encompass the prophylactic use of aspirin, control of hypertension and hyperlipidemia, and smoking cessation. Furthermore, the guidelines also recommend the prevention and treatment of macrovascular diseases. The latter include early detection and treatment for retinopathy and nephropathy, routine food care, lifestyle modifications, treatment intensification and patient education for self-management of diabetes (4). To obtain a better understanding of the trends in quality of diabetes care and potential disparities among patient subgroups, we systematically analyzed the latest available data from a nationally representative sample.

\section{Methods}

Study participants

The National Health and Nutrition Examination Survey (NHANES) is conducted by the Centers for Disease Control and Prevention's (CDC) National Center for Health Statistics (NCHS). Survey respondents were selected using a complex, stratified, multistage probability sampling design of the US noninstitutionalized civilian population (5). Since 1999, NHANES has been implemented as a continuous, crosssectional annual survey, with data publicly released in 2-year cycles. Surveys data are gathered through detailed in-person home interviews, followed by standardized physical examinations conducted in mobile examination centers, and laboratory tests using blood and urine specimens provided by participants during the physical examination. The overall participant response rate ranged from $61.3 \%$ to $84 \%$ for interviews, and $68.5 \%$ to $80 \%$ for examinations at mobile 
examination centers (MECs) for each survey cycle from 1999 to 2016. The surveys were reviewed and approved by the NCHS Institutional Review Board (IRB) and informed consent was obtained from participants.

\section{Definition of diabetes}

Diabetes was defined if one or more of the following conditions were met: 1) a positive response to one or more of the following questions: "Other than during pregnancy, have you ever been told by a doctor that you have diabetes?", "Are you now taking insulin?", "Are you now taking diabetic pills to lower your blood sugar?"; 2) diabetes medication(s) reported and brought to examination by the interviewee; 3 ) fasting plasma glucose $\geq 7 \mathrm{mmol} / \mathrm{L} ; 4$ ) glycosylated hemoglobin ( $\mathrm{HbA1c}) \geq 6.5 \%$ $(6,7)$. All patients with diabetes aged 20 years and older at the time of the survey were included in this analysis.

\section{Predictor variables}

Race and ethnicity were self-reported and were grouped into four categories: whites, blacks, Hispanics, and others. Health insurance status is determined by response to the question "Are you covered by health insurance or some other kind of healthcare plan?" Participants with an affirmative answer were categorized into "insured" and negative answer "uninsured".

Socioeconomic status (SES) was measured using self-reported education and family income of the participant. Education categories included were "< high school," "high school graduate," "some college", and "college graduate or above". Poverty levels were computed from a ratio of family income to poverty threshold: Poverty Income Ratio (PIR). Values were grouped as "<100\% PIR," "100-299\% PIR," "300-499\% PIR" and " $\geq 500 \%$ PIR."

\section{Outcome variables}

Glycated hemoglobin (HbA1c) is the primary outcome measure used for monitoring the average blood glucose concentration in individuals with diabetes. The existence of hypertension as a co-morbidity of diabetes is damaging because of the negative health impact the two conditions have on cardiovascular events, neuropathy, retinopathy, and nephropathy (8). Diabetic dyslipidemia, characterized by high plasma triglyceride concentration, high Low-Density Lipoprotein Cholesterol (LDLC) and low High-Density Lipoprotein (HDL) concentration is another major risk factor for cardiovascular diseases in diabetes. Considering the risk factors for diabetes, we assessed the quality of care for diabetes and included the following quality indicators: $\mathrm{HbA} 1 \mathrm{c}<8 \%$, Blood Pressure (BP) $<130 / 80$ $\mathrm{mmHg}$, Low-Density Lipoprotein (LDL-C) $<100 \mathrm{mg} / \mathrm{dL}$, triglycerides $<150 \mathrm{mg} / \mathrm{dL}$, receipt of eye in the past year, foot examinations in the past year, and meeting with a diabetes educator in the past year.

$\mathrm{HbA1c}$ was examined in this analysis as both continuous and binary variables. A reasonable goal of $<7 \%$ is defined by American Diabetes Association (ADA) for nonpregnant adults.
However, ADA recommends a less stringent goal of $<8 \%$ based on variation in life expectancies, number of co-morbid conditions, and duration of diabetes (9). Glycemic control of < $8 \%$ was added in response to previous studies that reported older adults with diabetes are less likely to benefit from stringent HbA1c management (10). For this study, HbA1c of > $8 \%$ was considered suitable for uncontrolled diabetes taking into account this variability.

Mean systolic and diastolic blood pressure (BP) were determined per NHANES reporting guidelines. Up to 3 BP readings were obtained and used to calculate a mean systolic $\mathrm{BP}$ and a mean diastolic BP for each individual. A detailed description of the procedures for BP measurement in NHANES has been published elsewhere (11). Hypertension control was defined as SBP $<130 \mathrm{~mm} \mathrm{Hg}$ and DBP $<80 \mathrm{~mm} \mathrm{Hg}$ (12).

The 2013 American College of Cardiology (ACC)/American Heart Association (AHA) guidelines define low-density lipoprotein cholesterol (LDL-C) goal of $<100 \mathrm{mg} / \mathrm{dL}$ and a goal of $<150$ $\mathrm{mg} / \mathrm{dL}$ for triglycerides recommended for patients with diabetes (13). Total cholesterol and HDL-C were measured directly through NHANES data collection. LDL-C levels were estimated for people who fasted properly (for $\geq 8$ hours and < 24 hours) using the following equation [LDL cholesterol = (total cholesterol) - (HDL cholesterol) - (triglycerides/5)]. Estimates for the prevalence of achieving valid LDL-C was based on the fasting sample only.

Receipt of eye examination was evaluated based on participants' response to a question "When was the last time you had an eye exam in which the pupils were dilated?". If participants reported receiving an eye exam within the past year then eye exam was coded as "yes". Respondents were considered to have had foot examination if they responded once or more to the question "During the past 12 months, about how many times has a doctor or other health professional checked feet for any sores or irritations?". Meeting with a diabetes educator in the past year was based on the question: "When was the last time you saw a diabetes nurse educator, dietician, or nutritionist?" and was coded as "Yes" for the response was "less than one year" and "no" for "more than one year".

\section{Covariates}

Respondents' age, gender, marital status, smoking status, Body Mass Index (BMI), utilization of diabetes medications, statin use and history of physician-diagnosed cardiovascular disease (CVD) (including stroke, congestive heart failure, angina pectoris, myocardial infarction, or coronary artery disease) were obtained through a questionnaire.

Hypertension was defined if one or more of the following conditions were met: 1 ) systolic $B P \geq 140 \mathrm{~mm} \mathrm{Hg}$; 2) diastolic BP $\geq 90 \mathrm{~mm} \mathrm{Hg}$; and an affirmative response to "Are you currently taking medication to lower your blood pressure?" (12). 
Chronic kidney disease (CKD) was defined as either an estimated glomerular filtration rate (eGFR) $<60 \mathrm{~mL}^{-1} \mathrm{~min}^{-1} 1.73$ $\mathrm{m}^{2}$ or a urinary albumin concentration of $>200 \mathrm{mg} \mathrm{g}^{-1}$ urinary creatinine, where eGFR was estimated using the Chronic Kidney Disease Epidemiological Collaboration equation (14). Serum creatinine levels from 1999-2000 and 2005-2006 were calibrated as per NHANES documentation (15). Albuminuria was defined as Albumin-to-Creatinine ratio $>30 \mathrm{mg} \mathrm{g}^{-1}$ (16).

\section{Statistical Methods}

Descriptive statistics were used to assess the differences in sociodemographic and clinical characteristics. Appropriate sampling weights were used to account for differential probabilities of selection and the complex multistage sampling design. Additional sample weights were used to account for non-response and missing data. Taylor linearization was used for variance estimation and domain analysis was used for subpopulation analyses because selection of subpopulations may be unrelated to sample design. Trends in the performance of quality indicators for diabetes care were assessed with SAS survey procedures (PROC SURVEYREG and PROC SURVEYLOGISITC). To examine the factors affecting the quality of diabetes care, adjusted logistic regression models were constructed with quality indicators as the dependent variable and odds ratios and $95 \%$ confidence intervals were estimated. All the statistical analyses were conducted using SAS (version 9.4.3, SAS Institute Inc., Cary, NC, USA) with a level of significance set at 0.05 .

\section{Results}

A total of 7,521 adults with diabetes were identified and included in the analysis. A significant rise in the proportion of adults with some college education ( $25.8 \%$ to $32.4 \%$; $P_{\text {trend }}<$ $0.001)$ and individuals who were college graduates $(14.6 \%$ to 21.3\%; Ptrend $<0.001$ ) was observed during the study period (Supplemental table 1). During the same time, the percentage of whites decreased from $63.8 \%$ to $58.2 \%\left(P_{\text {trend }}=0.01\right)$.

Improvements were observed in meeting the HbA1c goals in many patient subgroups, such as individuals with less than high school education $\left(66.8 \%\right.$ to $\left.71.2 \%, P_{\text {trend }}<0.001\right)$, those with a PIR of $<100 \%$ (67.8\% to $\left.71.5 \%, \mathrm{P}_{\text {trend }}=0.02\right)$, insured participants (from $75.4 \%$ to $82.5 \%$; $P_{\text {trend }}<0.001$ ) and adults taking oral diabetes medications ( $72.6 \%$ to $84 \%$; Ptrend $<0.001$ ) (Table 1 ). Significant increase in achieving BP goals were noted for whites $(44.5 \%$ to $53.8 \%$; Ptrend $=0.01)$, blacks $(43.8 \%$ to $53.3 \%$; $\left.P_{\text {trend }}=0.03\right)$, as well as for adults with insurance $(47.0 \%$ to $57.4 \%$; $P_{\text {trend }}<0.001$ ) (Table 2).

The overall rates of achieving LDL-C and triglycerides goals were 46.6\% (Table 3) and 53.0\% (Table 4), respectively. The rate of meeting LDL-C goal improved significantly for whites (34.6\% to $56.9 \%$; $\left.P_{\text {trend }}<0.001\right)$, blacks $\left(27.9 \%\right.$ to $45.5 \%$; $\left.P_{\text {trend }}=0.02\right)$, insured $\left(41.7 \%\right.$ to $\left.54.0 \% ; P_{\text {trend }}=0.02\right)$, and statin users $(45.7 \%$ to 72.1\%; Ptrend $<0.01$ ). (Table 3). Significant improvement in triglyceride control was observed among individuals with PIR
$<100 \%$ (32.0\% to 51.0\%; $\left.P_{\text {trend }}=0.01\right)$, insured individuals $(47.0 \%$ to $\left.60.8 \% P_{\text {trend }}=0.02\right)$, statin users $\left(49.5 \%\right.$ to $64.2 \%$; $\left.P_{\text {trend }}=0.02\right)$ and for those with certain comorbidities: hypertension $(45.4 \%$ to $59.5 \%$; Ptrend $=0.03)$, chronic kidney disease $(46.4 \%$ to $64.7 \%$; $\left.P_{\text {trend }}<0.001\right)$, and cardiovascular disease $(40.1 \%$ to 55.9\%; Ptrend $=0.02$ ) (Table 4).

Table 5 presents adjusted results evaluating the impact of sociodemographic and clinical characteristics on quality of diabetes care. Older ( $\geq 60$ years) individuals with diabetes were $74.7 \%$ more likely to have controlled HbA1c levels and $36 \%$ less likely to meet BP goal when compared with their younger con. Compared to patients with less than high school education, college graduates were $41.5 \%$ more likely to achieve $\mathrm{HbA} 1 \mathrm{c}$ goal $(P=0.03)$. The likelihood of achieving HbA1c and BP goals was found to be lower among blacks, Hispanics and individuals without insurance. Patients taking oral diabetes medications were 2.4 times more likely to have achieved HbA1c goal compared to untreated $(P<0.001)$.

Compared with their younger counterparts, individuals aged 60 year or over were $23.6 \%$ less likely to achieve triglycerides goal $(P=0.02)$ but were $26.5 \%$ more likely to achieve LDL-C goal. Although blacks were less likely to meet LDL-C goal than whites, the likelihood of achieving triglyceride goal was found to be 3.6 times higher among blacks. The likelihood of meeting guideline recommended triglyceride goal also decreased with elevated BMI. The likelihoods of receiving eye examination, foot examination and meeting with a diabetes educator were substantially higher among older adults. Blacks were $41.9 \%$ more likely $(P=0.01)$ and Hispanics $17.3 \%$ less likely $(P=0.03)$ than whites to have foot examination over the past year.

\section{Discussion}

The current cross-sectional study was based on National Health and Nutrition Examination Survey from 1999 to 2016 and evaluated trends and disparities in the quality for diabetes care. The results showed an overall improvement in diabetes management during the study period as indicated by the proportion of respondents meeting $\mathrm{HbA} 1 \mathrm{c}, \mathrm{BP}, \mathrm{LDL}-\mathrm{C}$ and triglyceride goals. We observed that the prevalence of diabetes increased with lower education, as well as an upward trend in percentage of Hispanics with diabetes over the study period. These changes are likely attributable to inadequate insurance coverage, lack of health knowledge, and resultant suboptimal diabetes preventive care and management, all of which are particularly prevalent among Hispanic populations $(3,16,17)$.

Over the past decades, numerous efforts have been made nationwide to reduce disparities in diabetes care $(2-4,7)$ and national treatment guidelines revised toward race-specific treatment paradigms $(11,12,15)$. Despite these efforts, substantial gaps in diabetes treatment and outcomes persist in US populations. Overall, whites were more likely to have achieved most diabetes care goals than minorities. Blacks exhibited normal triglyceride levels that is attributable to higher 
lipase activity among them (17). There has been a significant increase in the use of statin over the past few decades which is associated with paralleled decrease in LDL-C and triglycerides levels observed in our study.

Despite continuous innovation in glucose-lowering medications, the overall declining glycemic control may be due to changes in the characteristics of adults with type 2 diabetes and increase in patient cost sharing in U.S. healthcare plans (19). In general, significantly higher rates of uncontrolled BP, LDL-C and triglyceride levels were observed among Hispanics, adults with low SES, uninsured populations, individuals not taking statins or diabetes medications and adults with certain comorbid conditions such as hypertension and cardiovascular disease. Improvement in $\mathrm{HbA1c}$, BP and lipid profile observed during the study period reflects availability of innovative diabetes medications. Yet a substantial proportion of adults with diabetes, particularly blacks and Hispanics were less likely to meet the recommended goals (20-22).

Suboptimal insurance coverage and lower socioeconomic status are among the strongest predictors of poor quality of diabetes care. After adjusting for confounders, older adults, whites, individuals with higher educational status, and adults with insurance were more likely to meet the HbA1c goal. In our study, SES had a significant impact on meeting $\mathrm{HbA1C}, \mathrm{BP}$ and LDL-C goals. Other studies have reported a decline in the proportion of patients with poor BP between 1988-2008; however, SES-related disparities remained $(22,23,24)$. Lack of health insurance and presence of comorbidities were found to be associated with lower rates of eye and foot examination. The reasons for these persistent disparities are complex and further research is needed to understand the mechanism underlying these disparities.

In our study, the likelihood of receiving eye checkups increased with age, this is likely attributable to the higher prevalence of diabetes retinopathy among older patients (24). Similarly, older adults were more likely to have their feet checked for sores. Given that the risk of lower extremity amputations increases with age and duration of diabetes, routine foot examination for sores or irritation effectively reduces such risks (25). The greater prevalence of diabetes and diabetic complications among older adults, is also indicative of the higher likelihood of meeting with a diabetes educator, particularly as the disease may become more advanced with older age.
Strengths and Limitations

A strength of this study was the use of a nationally representative sample allowing generalization to the US adult noninstitutionalized population. Health care utilization information and clinical outcomes were assessed using standardized procedures, which allows us to better characterize diabetes management. The nature of NHANES data opens the study to several limitations. This is a serial crosssectional study with inherent limitations due to observational study design and residual confounding. Respondents were less likely to report their exact income thus resulting in potential misclassification. Insurance was dichotomized as 'insured' versus 'uninsured' and did not account for specific insurance types. Some important causal relationships such as lifestyle characteristics and quality of diabetes care cannot be examined although educational status and healthcare utilization are shown to be heavily correlated with lifestyles (29). Also the report of drug use only includes prescription medications that have been used in the past 30 days. Moreover, the recordings of $\mathrm{BP}$ represent one-day measurements as opposed to average measurement from several visits as recommended by 2017 American College of Cardiology/American Heart Association Guidelines.

\section{Conclusion}

The findings from this study provide insight into the current status and trends of quality of diabetes care in the US. The study results highlight persistent sociodemographic disparities and areas for improvement in diabetes management. Implementations of various guidelines to advance quality of diabetes care are among the many efforts to improve treatment outcomes of diabetes. Despite these efforts and overall improvements, suboptimal outcomes in diabetes care were still observed among blacks and Hispanics, uninsured populations and other socioeconomically disadvantaged groups. Targeted prevention approaches and disease management paradigm are needed for high-risk populations to achieve improved quality and equity in diabetes care.

Authorship statement: Part of this work was presented at the International Society for Pharmacoeconomic and Outcomes Research (ISPOR) 2019 Annual Meeting in New Orleans, LA. The authors accept responsibility for the scientific content of the manuscript.

\section{Conflict of Interests: None}

Funding: None 


\section{References}

1. National Diabetes Statistics Report | Data \& Statistics | Diabetes | CDC [Internet]. 2018 [cited 2019 Feb 7]. Available from: https://www.cdc.gov/diabetes/data/statistics/statistics-report.html

2. Saaddine JB, Cadwell B, Gregg EW, Engelgau MM, Vinicor F, Imperatore G, et al. Improvements in Diabetes Processes of Care and Intermediate Outcomes: United States, 1988-2002. Ann Intern Med. 2006;144 (7):465-74.

3. Harris CD, Pan L, Mukhtar Q. Changes in receiving preventive care services among US adults with diabetes, 1997-2007. Prev Chronic Dis. 2010;7(3):A56.

4. Vijan S, Stevens DL, Herman WH, Funnell MM, Standiford CJ. Screening, Prevention, Counseling, and Treatment for the Complications of Type II Diabetes Mellitus. J Gen Intern Med. 1997;12(9):567-80.

5. NHANES Survey Methods and Analytic Guidelines [Internet]. [cited 2019 Feb 7]. Available from: https://wwwn.cdc.gov/nchs/nhanes/analyticguidelines.aspx

6. Association AD. 2. Classification and Diagnosis of Diabetes. Diabetes Care. 2016 Jan 1;39(Supplement 1):S13-22.

7. Gregg EW, Cadwell BL, Cheng YJ, Cowie CC, Williams DE, Geiss L, et al. Trends in the Prevalence and Ratio of Diagnosed to Undiagnosed Diabetes According to Obesity Levels in the U.S. Diabetes Care. 2004;27(12):2806-12.

8. Sowers JR, Epstein M, Frohlich ED. Diabetes, Hypertension, and Cardiovascular Disease: An Update. Hypertension. 2001;37(4):1053-9.

9. American Diabetes Association. 5. Glycemic Targets. Diabetes Care. 2016;39 Suppl 1:S39-46.

10. Meneilly, G. S., \& Tessier, D. (2001). Diabetes in Elderly Adults. The Journals of Gerontology: Series A, 56(1), M5-M13. https://doi.org/10.1093/gerona/56.1.M5

11. National Center for Health Statistics. NHANES Health Tech/Blood Pressure Procedures Manual. https://www.cdc.gov/nchs/data/nhanes/nhanes 09 10/BP.pdf. Accessed February 14, 2019.

12. Chobanian AV, Bakris GL, Black HR, Cushman WC, Green LA, Izzo JL, et al. Seventh Report of the Joint National Committee on Prevention, Detection, Evaluation, and Treatment of High Blood Pressure. Hypertension. 2003;42(6):1206-52.

13. Stone NJ, Robinson J, Lichtenstein AH, Merz CNB, Blum CB, Eckel RH, et al. 2013 ACC/AHA Guideline on the Treatment of Blood Cholesterol to Reduce Atherosclerotic Cardiovascular Risk in Adults: A Report of the American College of Cardiology/American Heart Association Task Force on Practice Guidelines. Circulation. 2014;129[suppl 2]:S1-S45.

14. Levey AS, Stevens LA, Schmid CH, Zhang Y (Lucy), Castro AF, Feldman HI, et al. A New Equation to Estimate Glomerular Filtration Rate. Ann Intern Med. 2009;150(9):604-12.

15. Selvin E, Manzi J, Stevens LA, Van Lente F, Lacher DA, Levey AS, et al. Calibration of serum creatinine in the National Health and Nutrition Examination Surveys (NHANES) 1988-1994, Am J Kidney Dis. 2007;50(6):918-26.

16. National Kidney Foundation. KDOQI Clinical Practice Guideline for Diabetes and CKD: 2012 Update. Am J Kidney Dis. 2012;60(5):850-86.

17. Smith J. Diabetes and the Rise of the SES Health Gradient [Internet]. Cambridge, MA: National Bureau of Economic Research; 2007 Feb [cited $2018 \mathrm{Jul}$ 25]. Available from: http://www.nber.org/papers/w12905.pdf

18. Casagrande SS, Cowie CC. Health Insurance Coverage Among People With and Without Diabetes in the U.S. Adult Population. Diabetes Care. 2012;35(11):2243-9.

19. Tang KL, Barnieh L, Mann B, Clement F, Campbell DJT, Hemmelgarn BR, et al. A systematic review of value-based insurance design in chronic diseases. Am J Manag Care. 2014;20(6):e229-241.

20. Kirk JK, D'Agostino RB, Bell RA, Passmore LV, Bonds DE, Karter AJ, et al. Disparities in HbA1c Levels Between African-American and Non-Hispanic White Adults With Diabetes. Diabetes Care. 2006;(9):2130-6.

21. Toth $\mathrm{P}$, Henriksson KM, Palmer MK. Treatment patterns and LDL-C goal attainment in patients with diabetes: Temporal trends analysis from National Health and Nutrition Examination Survey†. J Clin Lipidol. 2016;10(3):708.

22. Carroll M, Kit B, Lacher D. Trends in elevated triglyceride in adults: United States, 2001-2012. NCHS Data Brief. 2015;(198):198.

23. Doucette ED, Salas J, Scherrer JF. Insurance coverage and diabetes quality indicators among patients in NHANES. Am J Manag Care. 2016 Jul;22(7):484-90.

24. Chatterji P, Joo H, Lahiri K. Racial/Ethnic- and Education-Related Disparities in the Control of Risk Factors for Cardiovascular Disease Among Individuals With Diabetes. Diabetes Care. 2012;35(2):305-12.

25. Leng B, Jin Y, Li G, Chen L, Jin N. Socioeconomic status and hypertension: a meta-analysis. J Hypertens. 2015;33(2):221-9.

26. Després JP, Couillard C, Gagnon J, Bergeron J, Leon AS, Rao DC, et al. Race, visceral adipose tissue, plasma lipids, and lipoprotein lipase activity in men and women: the Health, Risk Factors, Exercise Training, and Genetics (HERITAGE) family study. Arterioscler Thromb Vasc Biol. 2000;20(8):1932-8.

27. Gu A, Kamat S, Argulian E. Trends and disparities in statin use and low-density lipoprotein cholesterol levels among US patients with diabetes, 1999-2014. Diabetes Research and Clinical Practice. 2018;139:1-10.

28. Kato S, Takemori M, Kitano S, Hori S, Fukushima H, Numaga J, et al. Retinopathy in older patients with diabetes mellitus. Diabetes Res Clin Pract. 2002; 58(3):187-92.

29. Centers for Disease Control and Prevention (CDC). Lower extremity disease among persons aged $>$ or $=40$ years with and without diabetes--United States, 1999-2002. MMWR Morb Mortal Wkly Rep. 2005;54(45):1158-60.

30. Lee IC, Chang CS, Du PL. Do healthier lifestyles lead to less utilization of healthcare resources? BMC Health Serv Res 2017; $31 ; 17(1): 243$. 
Table 1. Prevalence of Controlled Hemoglobin A1C (HbA1c $<$ 8\%) among Adults with Diabetes-NHANES, $1999-2016$

\begin{tabular}{|c|c|c|c|c|c|}
\hline Variables & $\begin{array}{c}\text { Overall } \\
(n=7521)\end{array}$ & $\begin{array}{c}1999-2004 \\
(n=1960)\end{array}$ & $\begin{array}{c}2005-2010 \\
(n=2663)\end{array}$ & $\begin{array}{c}2011-2016 \\
(n=2898)\end{array}$ & $\begin{array}{c}\mathbf{P}_{\text {trend }} \\
\text { (adjusted) }\end{array}$ \\
\hline All patients & $75.4(0.8)$ & $71.9(1.4)$ & $74.0(1.2)$ & $79.9(1.4)$ & $<0.001$ \\
\hline \multicolumn{6}{|l|}{ Race and ethnicity } \\
\hline Whites & $79.5(1.0)$ & $76.3(2.0)$ & $82.0(3.0)$ & $85.7(3.0)$ & $<0.01$ \\
\hline Blacks & $71.3(1.1)$ & $65.3(3.0)$ & $70.7(1.6)$ & $75.5(1.6)$ & 0.03 \\
\hline Hispanics & $64.1(1.6)$ & $59.3(3.4)$ & $68.6(3.0)$ & $67.5(2.4)$ & 0.39 \\
\hline Others & $73.8(2.8)$ & $70.5(1.8)$ & $78.5(1.3)$ & $79.7(1.8)$ & 0.45 \\
\hline \multicolumn{6}{|l|}{ Education } \\
\hline Less than high school & $72.6(1.2)$ & $66.8(2.1)$ & $70.6(1.8)$ & $71.2(2.1)$ & $<0.001$ \\
\hline High school graduate & $73.3(1.4)$ & $70.0(2.2)$ & $72.0(2.2)$ & $76.2(2.5)$ & 0.09 \\
\hline Some college & $77.6(1.3)$ & $72.5(2.8)$ & $79.0(1.9)$ & $78.0(2.0)$ & 0.12 \\
\hline College graduate or above & $84.7(1.7)$ & $83.9(3.5)$ & $84.1(2.7)$ & $86.0(2.6)$ & 0.21 \\
\hline \multicolumn{6}{|l|}{ Poverty-to-income ratio (PIR) } \\
\hline$<100 \%$ & $70.1(1.4)$ & $67.8(3.3)$ & $69.9(2.4)$ & $71.5(2.0)$ & 0.02 \\
\hline $100 \%-299 \%$ & $74.0(1.1)$ & $72.0(2.2)$ & $70.1(1.4)$ & $78.2(2.0)$ & 0.12 \\
\hline $300 \%-499 \%$ & $76.3(1.8)$ & $71.8(3.8)$ & $81.9(2.3)$ & $79.8(2.0)$ & 0.56 \\
\hline$\geq 500 \%$ & $79.5(1.9)$ & $73.9(3.2)$ & $83.8(2.8)$ & $83.6(3.5)$ & 0.77 \\
\hline \multicolumn{6}{|l|}{ Insurance } \\
\hline Insured & $78.3(2.2)$ & $75.4(1.5)$ & $76.7(1.2)$ & $82.5(1.3)$ & $<0.001$ \\
\hline Uninsured & $61.9(0.8)$ & $57.2(3.1)$ & $67.9(2.9)$ & $59.6(3.6)$ & 0.11 \\
\hline \multicolumn{6}{|l|}{ Diabetes medication } \\
\hline Oral medications only & $80.0(0.9)$ & $72.6(1.9)$ & $80.9(1.3)$ & $84.0(1.4)$ & $<0.001$ \\
\hline Insulin only & $58.0(2.2)$ & $54.9(3.4)$ & $56.2(4.2)$ & $61.1(3.5)$ & 0.32 \\
\hline Oral medications and insulin & $51.6(2.4)$ & $49.6(4.8)$ & $46.3(3.8)$ & $59.8(3.4)$ & 0.21 \\
\hline None & $85.6(1.1)$ & $84.6(1.9)$ & $89.3(1.6)$ & $82.7(2.0)$ & 0.32 \\
\hline \multicolumn{6}{|l|}{ Statin use } \\
\hline Yes & $79.2(1.2)$ & $74.1(2.7)$ & $80.2(1.4)$ & $86.7(2.4)$ & 0.01 \\
\hline No & $70.2(1.1)$ & $69.3(1.6)$ & $71.5(1.8)$ & $70.3(2.3)$ & 0.44 \\
\hline \multicolumn{6}{|l|}{ Co-morbidities } \\
\hline Hypertension & $75.1(1.6)$ & $74.5(1.5)$ & $76.2(1.1)$ & $76.7(1.5)$ & 0.16 \\
\hline Chronic kidney disease & $72.4(1.0)$ & $69.2(2.7)$ & $76.2(1.9)$ & $69.6(2.4)$ & 0.52 \\
\hline Cardiovascular disease & $70.5(1.5)$ & $70.7(1.3)$ & $68.0(1.4)$ & $71.8(1.5)$ & 0.70 \\
\hline Albuminuria & $65.3(1.4)$ & $63.4(2.5)$ & $63.9(2.0)$ & $62.7(2.4)$ & 0.33 \\
\hline
\end{tabular}


Table 2. Prevalence of Controlled Blood Pressure (<130/80 mm Hg) among Adults with Diabetes-NHANES, $1999-2016$

\begin{tabular}{|c|c|c|c|c|c|}
\hline Variables & $\begin{array}{c}\text { Overall } \\
(n=7521)\end{array}$ & $\begin{array}{c}1999-2004 \\
(n=1960)\end{array}$ & $\begin{array}{c}2005-2010 \\
(n=2663)\end{array}$ & $\begin{array}{c}2011-2016 \\
(n=2898)\end{array}$ & $\begin{array}{c}P_{\text {trend }} \\
\text { (adjusted) }\end{array}$ \\
\hline All patients & $51.3(0.8)$ & $42.3(1.8)$ & $48.8(1.3)$ & $51.2(1.4)$ & $<0.001$ \\
\hline \multicolumn{6}{|l|}{ Race and ethnicity } \\
\hline Whites & $51.4(1.3)$ & $44.5(2.7)$ & $51.8(1.9)$ & $53.8(2.1)$ & 0.01 \\
\hline Blacks & $44.4(1.5)$ & $43.8(1.5)$ & $49.6(1.9)$ & $53.3(2.2)$ & 0.03 \\
\hline Hispanics & $40.5(1.2)$ & $36.8(2.6)$ & $42.8(1.7)$ & $40.7(2.1)$ & 0.26 \\
\hline Others & $53.3(1.6)$ & $41.2(2.9)$ & $52.6(2.0)$ & $59.8(2.3)$ & $<0.001$ \\
\hline \multicolumn{6}{|l|}{ Education } \\
\hline Less than high school & $44.2(1.3)$ & $37.1(2.2)$ & $44.4(2.0)$ & $47.8(2.3)$ & $<0.001$ \\
\hline High school graduate & $46.1(1.5)$ & $42.4(3.0)$ & $46.4(2.2)$ & $48.6(2.7)$ & 0.18 \\
\hline Some college & $50.2(1.6)$ & $44.5(3.3)$ & $53.4(2.5)$ & $50.8(2.4)$ & 0.42 \\
\hline College graduate or above & $55.4(2.2)$ & $50.6(4.7)$ & $60.4(4.0)$ & $54.2(3.1)$ & 0.28 \\
\hline \multicolumn{6}{|l|}{ Poverty-to-income ratio (PIR) } \\
\hline$<100 \%$ & $44.5(1.6)$ & $38.5(2.8)$ & $46.0(3.2)$ & $47.1(2.4)$ & 0.02 \\
\hline $100 \%-299 \%$ & $46.5(1.2)$ & $40.0(2.4)$ & $48.9(1.6)$ & $50.1(2.0)$ & $<0.001$ \\
\hline $300 \%-499 \%$ & $54.0(2.0)$ & $49.4(5.1)$ & $54.9(3.9)$ & $55.7(3.8)$ & 0.45 \\
\hline$\geq 500 \%$ & $50.0(2.6)$ & 44.5 (1.9) & $54.1(1.9)$ & $50.6(2.0)$ & 0.75 \\
\hline \multicolumn{6}{|l|}{ Insurance } \\
\hline Insured & $54.3(1.9)$ & $47.0(2.0)$ & $54.0(1.5)$ & $57.4(1.4)$ & $<0.001$ \\
\hline Uninsured & $45.6(0.9)$ & $46.8(4.6)$ & $45.5(2.8)$ & $44.6(3.0)$ & 0.35 \\
\hline \multicolumn{6}{|l|}{ Statin use } \\
\hline Yes & $57.9(1.4)$ & $42.9(3.6)$ & $56.2(2.0)$ & $61.9(2.3)$ & 0.03 \\
\hline No & $45.8(1.2)$ & $42.1(2.1)$ & $42.1(1.7)$ & $47.3(2.4)$ & 0.07 \\
\hline \multicolumn{6}{|l|}{ Diabetes Medication } \\
\hline Oral medications only & $51.0(1.2)$ & $45.6(2.1)$ & $54.0(2.1)$ & $50.4(2.0)$ & 0.22 \\
\hline Insulin & $57.4(2.5)$ & $52.2(4.5)$ & $59.0(3.8)$ & $59.0(4.4)$ & 0.47 \\
\hline Oral medication and insulin & $54.4(2.3)$ & $47.8(5.3)$ & $51.6(3.1)$ & $58.8(3.3)$ & $<0.01$ \\
\hline None & $47.8(2.0)$ & $47.2(1.4)$ & $44.3(3.7)$ & $49.5(2.9)$ & 0.18 \\
\hline \multicolumn{6}{|l|}{ Co-morbidities } \\
\hline Hypertension & $31.5(0.9)$ & $22.8(1.8)$ & $34.2(1.2)$ & $34.4(1.6)$ & $<0.01$ \\
\hline Chronic Kidney Disease & $37.9(1.4)$ & $30.9(3.5)$ & $41.7(2.1)$ & $38.7(2.0)$ & 0.29 \\
\hline Cardiovascular disease & $49.4(1.1)$ & $38.2(2.9)$ & $45.9(2.1)$ & $50.4(2.7)$ & 0.05 \\
\hline Albuminuria & $31.3(1.4)$ & $28.3(2.8)$ & $37.2(2.1)$ & $28.3(2.2)$ & 0.08 \\
\hline Data are presented as perce & tandard Fr & & & & \\
\hline
\end{tabular}


Table 3. Prevalence of Controlled LDL-C (<100 mg/dL) among Adults with Diabetes -NHANES, 1999-2014

\begin{tabular}{|c|c|c|c|c|c|c|}
\hline Variables & $\begin{array}{c}\text { Overall } \\
(n=2750)\end{array}$ & $\begin{array}{c}1999-2002 \\
(n=454)\end{array}$ & $\begin{array}{c}2003-2006 \\
(n=543)\end{array}$ & $\begin{array}{c}2007-2010 \\
(n=910)\end{array}$ & $\begin{array}{c}2011-2014 \\
(n=843)\end{array}$ & $\begin{array}{c}P_{\text {trend }} \\
\text { (adjusted) }\end{array}$ \\
\hline All patients & $46.6(1.3)$ & $31.9(3.4)$ & $44.2(2.7)$ & $50.5(2.4)$ & $52.5(2.2)$ & $<0.001$ \\
\hline \multicolumn{7}{|l|}{ Race and ethnicity } \\
\hline Whites & $49.7(1.4)$ & $34.6(5.0)$ & $45.4(3.6)$ & $55.5(3.3)$ & $56.9(3.3)$ & $<0.001$ \\
\hline Blacks & $40.5(5.0)$ & $27.9(0.8)$ & $39.7(1.7)$ & $40.6(1.4)$ & $45.5(1.6)$ & 0.02 \\
\hline Hispanics & $36.6(4.0)$ & $24.7(2.2)$ & $37.6(2.1)$ & $41.4(3.6)$ & $33.9(4.6)$ & 0.48 \\
\hline Others & $47.5(2.4)$ & $33.8(3.2)$ & $40.5(3.9)$ & $51.3(2.8)$ & $52.6(3.7)$ & 0.12 \\
\hline \multicolumn{7}{|l|}{ Education } \\
\hline Less than high school & $45.2(0.8)$ & $29.5(1.2)$ & $42.8(1.6)$ & $48.6(1.6)$ & $49.4(1.4)$ & $<0.01$ \\
\hline High school graduate & $46.5(1.0)$ & $34.8(3.0)$ & $41.7(1.7)$ & $57.8(2.5)$ & $46.1(1.9)$ & 0.24 \\
\hline Some college & $47.6(1.1)$ & $24.9(1.5)$ & $46.7(1.7)$ & $47.9(1.7)$ & $57.3(2.1)$ & 0.03 \\
\hline College graduate or above & $55.6(0.8)$ & $48.0(1.7)$ & $47.8(1.8)$ & $50.9(3.0)$ & $52.4(2.3)$ & 0.19 \\
\hline \multicolumn{7}{|l|}{ Poverty-to-income ratio (PIR) } \\
\hline$<100 \%$ & $37.4(0.6)$ & $20.4(1.3)$ & $32.7(1.2)$ & $41.6(1.4)$ & $45.6(2.2)$ & $<0.01$ \\
\hline $100 \%-299 \%$ & $46.3(1.3)$ & $31.3(1.2)$ & $39.3(1.3)$ & $48.6(1.7)$ & $50.7(1.7)$ & 0.03 \\
\hline $300 \%-499 \%$ & $50.7(1.0)$ & $40.2(2.6)$ & $47.5(1.9)$ & $55.9(2.0)$ & $59.6(3.0)$ & 0.01 \\
\hline$\geq 500 \%$ & $48.9(1.0)$ & $47.5(2.5)$ & $44.9(2.4)$ & $49.6(3.2)$ & $53.7(2.7)$ & 0.29 \\
\hline \multicolumn{7}{|l|}{ Insurance } \\
\hline Insured & $48.3(0.5)$ & $41.7(0.8)$ & $47.3(0.9)$ & $53.5(1.2)$ & $54.0(1.2)$ & 0.02 \\
\hline Uninsured & $35.1(1.3)$ & $29.1(1.1)$ & $32.3(1.7)$ & $35.7(1.9)$ & $33.6(1.9)$ & 0.95 \\
\hline \multicolumn{7}{|l|}{ Statin use } \\
\hline Yes & $68.6(1.0)$ & $45.7(2.9)$ & $65.9(1.5)$ & $71.3(2.0)$ & $72.1(2.2)$ & $<0.01$ \\
\hline No & $30.9(1.2)$ & $28.0(0.9)$ & $33.0(0.8)$ & $30.2(0.9)$ & $32.4(1.7)$ & 0.34 \\
\hline \multicolumn{7}{|l|}{ Diabetes Medication } \\
\hline Oral medications only & $52.5(1.5)$ & $34.8(0.8)$ & $50.0(1.2)$ & $53.8(1.6)$ & $59.6(1.5)$ & $<0.001$ \\
\hline Insulin & $55.3(0.7)$ & $24.3(2.6)$ & $64.9(2.5)$ & $59.0(3.9)$ & $51.1(4.1)$ & 0.10 \\
\hline Oral medication and insulin & $51.7(0.7)$ & $37.2(1.3)$ & $53.6(2.8)$ & $60.8(3.3)$ & $60.4(4.6)$ & 0.24 \\
\hline None & $39.2(0.9)$ & $27.9(2.6)$ & $38.1(1.2)$ & $42.1(2.1)$ & $40.1(1.9)$ & 0.48 \\
\hline \multicolumn{7}{|l|}{ Co-morbidities } \\
\hline Hypertension & $51.7(0.8)$ & $33.4(0.9)$ & $50.7(0.9)$ & $56.1(1.4)$ & $56.4(1.5)$ & 0.47 \\
\hline Chronic Kidney Disease & $53.6(1.3)$ & $38.0(1.2)$ & $51.9(1.9)$ & $60.6(2.3)$ & $61.9(2.1)$ & 0.16 \\
\hline Cardiovascular disease & $58.4(0.8)$ & $41.2(1.1)$ & $49.1(2.4)$ & $65.2(1.6)$ & $63.7(2.7)$ & 0.24 \\
\hline Albuminuria & $48.8(1.3)$ & $33.7(0.8)$ & $48.5(0.9)$ & $48.9(1.3)$ & $59.1(1.1)$ & 0.14 \\
\hline
\end{tabular}


Table 4. Prevalence of Controlled Triglycerides (<150 mg/dL) among Adults with Diabetes-NHANES 1999-2014

\begin{tabular}{|c|c|c|c|c|c|c|}
\hline Variables & $\begin{array}{c}\text { Overall } \\
(n=2750)\end{array}$ & $\begin{array}{c}1999-2002 \\
(n=454)\end{array}$ & $\begin{array}{c}2003-2006 \\
(n=543)\end{array}$ & $\begin{array}{c}2007-2010 \\
(n=910)\end{array}$ & $\begin{array}{c}2011-2014 \\
(n=843)\end{array}$ & $\begin{array}{c}\text { Ptrend } \\
\text { (adjusted) }\end{array}$ \\
\hline All patients & $53.0(1.5)$ & $45.4(2.9)$ & $47.6(2.9)$ & $55.8(2.1)$ & $58.8(3.5)$ & $<0.001$ \\
\hline \multicolumn{7}{|l|}{ Race and ethnicity } \\
\hline Whites & $50.8(1.6)$ & $43.0(1.1)$ & $47.5(1.4)$ & $54.6(1.5)$ & $56.9(2.3)$ & 0.02 \\
\hline Blacks & $72.4(0.8)$ & $62.4(1.5)$ & $68.6(1.9)$ & $72.9(2.2)$ & $79.9(2.5)$ & $<0.01$ \\
\hline Hispanics & $47.8(0.8)$ & $49.6(3.0)$ & $42.7(2.2)$ & $45.9(1.9)$ & $51.5(1.9)$ & 0.53 \\
\hline Others & $47.5(0.5)$ & $41.9(3.2)$ & $45.5(1.1)$ & $56.0(4.0)$ & $54.8(3.4)$ & 0.15 \\
\hline \multicolumn{7}{|l|}{ Education } \\
\hline Less than high school & $50.2(0.8)$ & $44.4(3.6)$ & $47.2(3.4)$ & $48.1(3.7)$ & $58.7(4.1)$ & 0.03 \\
\hline High school graduate & $51.8(0.9)$ & $45.5(5.7)$ & $47.0(4.5)$ & $57.5(3.0)$ & $57.8(4.4)$ & 0.02 \\
\hline Some college & $53.0(1.0)$ & $38.9(1.1)$ & $49.2(1.8)$ & $55.7(1.6)$ & $59.0(2.8)$ & $<0.01$ \\
\hline College graduate or above & $59.0(0.9)$ & $58.6(1.9)$ & $50.8(2.2)$ & $65.4(3.0)$ & $59.6(3.1)$ & 0.64 \\
\hline \multicolumn{7}{|l|}{ Poverty-to-income ratio (PIR) } \\
\hline$<100 \%$ & $47.8(0.7)$ & $32.0(1.3)$ & $40.1(1.6)$ & $49.0(1.2)$ & $51.0(2.5)$ & 0.01 \\
\hline $100 \%-299 \%$ & $54.5(1.3)$ & $50.9(1.5)$ & $49.5(1.8)$ & $54.7(1.4)$ & $60.9(2.0)$ & 0.14 \\
\hline $300 \%-499 \%$ & $51.0(1.0)$ & $41.2(1.6)$ & $45.0(2.1)$ & $58.5(2.0)$ & $51.3(2.7)$ & 0.12 \\
\hline$\geq 500 \%$ & $57.0(1.1)$ & $52.8(1.9)$ & $60.4(2.2)$ & $66.9(3.6)$ & $68.4(4.3)$ & 0.02 \\
\hline \multicolumn{7}{|l|}{ Insurance } \\
\hline Insured & $58.2(0.5)$ & $47.0(0.9)$ & $49.3(1.1)$ & $56.9(1.1)$ & $60.8(1.6)$ & 0.02 \\
\hline Uninsured & $45.0(1.6)$ & $42.5(2.2)$ & $36.7(1.7)$ & $50.5(1.8)$ & $49.2(1.8)$ & 0.54 \\
\hline \multicolumn{7}{|l|}{ Statin use } \\
\hline Yes & $56.1(1.1)$ & $49.5(3.0)$ & $54.5(1.2)$ & $57.1(1.3)$ & $64.2(1.2)$ & 0.02 \\
\hline No & $51.2(1.0)$ & $43.8(1.1)$ & $46.8(1.0)$ & $52.6(1.1)$ & $51.4(1.3)$ & 0.13 \\
\hline \multicolumn{7}{|l|}{ Diabetes Medication } \\
\hline Oral medications only & $52.3(1.5)$ & $40.9(0.9)$ & $46.5(1.3)$ & $53.5(1.3)$ & $61.6(2.1)$ & 0.03 \\
\hline Insulin & $67.1(0.7)$ & $69.5(1.8)$ & $56.2(2.7)$ & $61.3(3.9)$ & $68.0(4.2)$ & 0.55 \\
\hline Oral medication and insulin & $51.5(0.6)$ & $37.8(1.2)$ & $43.5(2.9)$ & $52.3(3.4)$ & $51.9(3.4)$ & 0.50 \\
\hline None & $54.9(1.0)$ & $50.9(2.5)$ & $49.4(2.1)$ & $59.8(2.4)$ & $55.9(2.4)$ & 0.44 \\
\hline \multicolumn{7}{|l|}{ Co-morbidities } \\
\hline Hypertension & $53.4(1.3)$ & $45.4(1.0)$ & $48.2(1.1)$ & $54.9(1.1)$ & $59.5(1.6)$ & 0.03 \\
\hline Chronic Kidney Disease & $56.3(1.4)$ & $46.4(1.6)$ & $56.3(1.9)$ & $61.3(1.5)$ & $64.7(2.2)$ & $<0.001$ \\
\hline Cardiovascular disease & $52.2(0.9)$ & $40.1(1.5)$ & $49.1(1.7)$ & $55.8(1.5)$ & $55.9(1.9)$ & 0.02 \\
\hline Albuminuria & $46.9(1.4)$ & $36.9(1.0)$ & $43.7(1.1)$ & $52.6(1.2)$ & $50.4(1.5)$ & 0.10 \\
\hline
\end{tabular}


Tables 5: Adjusted Odds Ratios for Achieving Quality Indicators for Diabetes Care among Adults with Diabetes, NHANES 1999-2016

\begin{tabular}{|c|c|c|c|c|c|c|c|}
\hline Variables & HbA1c $<8 \%$ & $\begin{array}{c}\text { BP }<130 / 80 \\
\mathrm{~mm} / \mathrm{Hg}\end{array}$ & $\begin{array}{c}\text { LDL-C }<100 \\
\mathrm{mg} / \mathrm{dL}\end{array}$ & $\begin{array}{l}\text { Triglycerides } \\
<150 \mathrm{mg} / \mathrm{dL} \text { ) }\end{array}$ & $\begin{array}{l}\text { Receipt of eye } \\
\text { examination }\end{array}$ & $\begin{array}{l}\text { Receipt of foot } \\
\text { examination }\end{array}$ & $\begin{array}{l}\text { Visited a diabetes } \\
\text { educator }\end{array}$ \\
\hline \multicolumn{8}{|l|}{ Age (ref: 20 to 39) } \\
\hline 40 to 59 & $1.08(0.76-1.54)$ & $0.97(0.71-1.32)$ & $0.70(0.42-1.19)$ & $0.61(0.39-1.26)$ & 1.62 (0.99-1.98) & $1.33(0.91-1.94)$ & $1.05(0.90-1.26)$ \\
\hline$\geq 60$ & $1.75(1.16-2.63)^{*}$ & $0.64(0.46-0.89)^{*}$ & $1.27(1.01-1.58)^{*}$ & $0.76(0.56-0.99)^{*}$ & $2.51(1.48-4.26)^{*}$ & $1.63(1.03-2.58)^{*}$ & $1.28(1.43-1.31)^{*}$ \\
\hline \multicolumn{8}{|l|}{ Gender } \\
\hline Women vs. men & $0.57(0.50-0.66)^{*}$ & $1.09(0.92-1.29)$ & $0.66(0.51-0.84)^{*}$ & $0.91(0.71-1.16)$ & $1.22(0.97-1.54)$ & $1.14(0.86-1.51)$ & $1.12(0.91-1.30)$ \\
\hline \multicolumn{8}{|l|}{$\begin{array}{l}\text { Educational status } \\
\text { (ref: < high school) }\end{array}$} \\
\hline $\begin{array}{l}\text { High school } \\
\text { graduate }\end{array}$ & $1.01(0.77-1.23)$ & $1.01(0.81-1.25)$ & $1.01(0.67-1.11)$ & $1.11(0.85-1.45)$ & $1.01(0.81-1.25)$ & $1.26(0.95-1.67)$ & $1.08(0.83-1.39)$ \\
\hline Some college & $1.03(0.78-1.26)$ & $1.15(0.93-1.43)$ & $1.40(0.62-1.42)$ & $1.23(0.93-1.61)$ & $1.15(0.93-1.43)$ & $1.29(0.93-1.77)$ & $1.18(0.90-1.53)$ \\
\hline $\begin{array}{l}\text { College } \\
\text { graduate or } \\
\text { above }\end{array}$ & $1.42(1.03-1.96)^{*}$ & $1.25(0.94-1.68)$ & $1.43(1.14-2.39)^{*}$ & $1.58(1.05-2.39)^{*}$ & $1.25(1.10-1.68)$ & $1.85(1.15-2.97)^{*}$ & $1.38(1.10-1.65)^{*}$ \\
\hline \multicolumn{8}{|l|}{$\begin{array}{l}\text { Poverty income-ratio } \\
\text { (ref: }<100 \%)\end{array}$} \\
\hline 100\%-299\% & $1.07(0.84-1.37)$ & $0.94(0.77-1.14)$ & $1.29(0.90-1.86)$ & $1.31(0.96-1.78)$ & $1.28(0.98-1.59)$ & $0.94(0.71-1.25)$ & $1.05(0.81-1.35)$ \\
\hline $300 \%-499 \%$ & $1.30(0.62-1.24)$ & $1.03(0.77-1.31)$ & 1.30 (1.00-2.10)* & $1.00(0.68-1.45)$ & 1.33 (1.11-2.11)* & $0.97(0.67-1.41)$ & $1.09(0.85-1.40)$ \\
\hline$\geq 500 \%$ & $1.60(0.64-1.34)$ & $1.13(0.58-1.08)$ & $1.41(0.80-2.50)$ & $1.32(0.86-2.12)$ & $1.40(0.84-1.97)$ & $1.40(0.90-2.18)$ & $1.33(1.06-1.54)$ \\
\hline \multicolumn{8}{|l|}{$\begin{array}{l}\text { Race and ethnicity } \\
\text { (ref: whites) }\end{array}$} \\
\hline Blacks & $0.77(0.63-0.96)^{*}$ & $0.75(0.63-0.89)^{*}$ & $0.68(0.51-0.90)^{*}$ & $3.61(2.63-4.95)^{*}$ & $1.37(1.06-1.78)^{*}$ & $1.42(1.07-1.88)$ & $1.40(1.12-1.75)^{*}$ \\
\hline Hispanics & $0.62(0.49-0.79)^{*}$ & $0.52(0.35-0.72)^{*}$ & $0.64(0.44-0.92)^{*}$ & $1.21(0.88-1.68)$ & $1.05(0.80-1.38)$ & $0.83(0.62-0.95)^{*}$ & $1.15(0.91-1.50)$ \\
\hline Others & $0.88(0.58-1.33)$ & $1.02(0.77-1.49)$ & $1.23(0.79-1.94)$ & $0.78(0.48-1.28)$ & $1.19(0.82-1.72)$ & $0.97(0.62-1.51)$ & $0.92(0.58-1.45)$ \\
\hline
\end{tabular}


Tables 5: Adjusted Odds Ratios for Achieving Quality Indicators for Diabetes Care among Adults with Diabetes, NHANES $1999-2016$ (continued)

\begin{tabular}{|c|c|c|c|c|c|c|c|}
\hline \multicolumn{8}{|l|}{ Insurance } \\
\hline $\begin{array}{l}\text { Uninsured vs. } \\
\text { insured }\end{array}$ & $0.56(0.44-0.72)^{*}$ & $0.81(0.62-0.99)^{*}$ & $0.78(0.58-0.82)^{*}$ & $0.74(0.53-0.85)^{*}$ & $0.81(0.62-0.92)^{*}$ & $0.53(0.38-0.74)^{*}$ & $1.04(0.73-1.55)$ \\
\hline \multicolumn{8}{|c|}{ BMI, kg/m² (ref:<25) } \\
\hline $25-<30$ & $1.06(0.76-1.46)$ & $1.22(0.95-1.57)$ & $0.83(0.56-1.31)$ & $0.56(0.39-0.80)^{*}$ & $0.78(0.56-1.09)$ & $0.75(0.51-1.11)$ & $0.94(0.75-1.25)$ \\
\hline$\geq 30$ & $0.84(0.61-1.17)$ & $1.29(0.96-1.53)$ & $0.89(0.59-1.35)$ & $0.50(0.36-0.71)^{*}$ & $0.90(0.65-1.24)$ & $0.82(0.54-1.25)$ & $1.12(1.01-1.34)^{*}$ \\
\hline \multicolumn{8}{|l|}{ Current smoker } \\
\hline Yes vs. no & $0.88(0.68-1.14)$ & $0.82(0.73-1.11)$ & $1.07(0.78-1.47)$ & $0.85(0.62-1.17)$ & $0.62(0.48-0.79)^{*}$ & $1.29(0.90-1.86)$ & $0.76(0.54-1.07)$ \\
\hline \multicolumn{8}{|l|}{ Statin use } \\
\hline Yes vs. no & $1.19(0.97-1.47)$ & $1.28(1.07-1.54)^{*}$ & $3.84(2.89-5.09)^{*}$ & $1.15(0.89-1.48)$ & $1.54(1.20-1.97)^{*}$ & $1.36(1.03-1.80)^{*}$ & $0.86(0.67-0.95)^{*}$ \\
\hline \multicolumn{8}{|c|}{$\begin{array}{l}\text { Diabetes education } \\
\text { (ref: none) }\end{array}$} \\
\hline $\begin{array}{l}\text { Oral } \\
\text { medications } \\
\text { only }\end{array}$ & $2.40(1.96-2.47)^{*}$ & $1.52(1.27-1.82)^{*}$ & $1.64(1.26-2.17)^{*}$ & $0.97(0.76-1.24)$ & $0.86(0.56-1.03)$ & $1.32(0.98-1.45)$ & $2.70(1.89-3.84)$ \\
\hline Insulin only & $1.60(1.40-1.80)^{*}$ & $0.95(0.77-1.09)$ & $0.97(0.80-1.03)$ & $0.92(0.84-1.09)$ & $1.79(1.38-2.59)^{*}$ & $2.72(1.86-4.02)^{*}$ & $1.37(0.95-1.66)$ \\
\hline $\begin{array}{l}\text { Oral } \\
\text { medications } \\
\text { and insulin }\end{array}$ & $1.32(0.93-1.37)$ & $1.03(0.89-1.33)$ & $1.13(0.96-1.26)$ & $1.02(0.91-1.18)$ & $1.00(0.92-1.24)$ & $1.20(0.84-1.03)$ & $1.40(1.27-1.68)$ \\
\hline \multicolumn{8}{|c|}{$\begin{array}{l}\text { Comorbidities (ref: } \\
\text { without comorbidity) }\end{array}$} \\
\hline Hypertension & $0.57(0.33-0.76)^{*}$ & $0.23(0.19-0.28)^{*}$ & $0.89(0.66-1.35)$ & $0.93(0.72-1.19)$ & $0.97(0.78-1.31)$ & $1.15(0.91-1.46)$ & $0.98(0.76-1.26)$ \\
\hline $\begin{array}{l}\text { Chronic kidney } \\
\text { disease }\end{array}$ & $0.89(0.70-1.15)$ & $0.95(0.77-1.16)$ & $1.01(0.71-1.39)$ & $1.19(0.88-1.60)$ & $1.04(0.82-1.29)$ & $1.41(1.01-1.97)$ & $1.30(0.99-1.73)$ \\
\hline $\begin{array}{l}\text { Cardiovascular } \\
\text { disease }\end{array}$ & $1.02(0.79-1.31)$ & $1.18(0.96-1.45)$ & $1.00(0.72-1.40)$ & $0.87(0.66-1.15)$ & $1.47(1.12-1.94)^{*}$ & $0.99(0.68-1.23)$ & $1.20(0.90-1.49)$ \\
\hline Albuminuria & $0.48(0.39-0.60)^{*}$ & $0.49(0.41-0.59)^{*}$ & $1.11(0.82-1.49)$ & $0.62(0.46-0.82)^{*}$ & $1.00(0.73-1.35)$ & $0.92(0.69-1.23)$ & $1.19(0.95-1.49)$ \\
\hline
\end{tabular}


Supplemental Table 1. Sociodemographic and Clinical Characteristics of Adults with Diabetes ( $\geq 20$ Years Old) -NHANES, $1999-2016$

\begin{tabular}{|c|c|c|c|c|c|c|c|c|c|}
\hline \multirow{3}{*}{ Variables } & \multirow{3}{*}{$\begin{array}{c}\text { Overall } \\
\%(95 \% \mathrm{CI}) \\
\mathrm{n}=7521 \\
\end{array}$} & \multirow{3}{*}{ SE } & \multirow{3}{*}{$\begin{array}{c}1999-2004 \\
\%(95 \% \mathrm{CI}) \\
\mathrm{n}=1960\end{array}$} & \multirow{3}{*}{ SE } & \multirow{3}{*}{$\begin{array}{c}2005-2010 \\
\%(95 \% \mathrm{CI}) \\
\mathrm{n}=2663 \\
\end{array}$} & \multirow{3}{*}{ SE } & \multirow{3}{*}{$\begin{array}{c}2011-2016 \\
\%(95 \% \mathrm{CI}) \\
\mathrm{n}=2898 \\
\end{array}$} & \multirow{3}{*}{ SE } & \multirow{3}{*}{$\mathbf{P}_{\text {trend }}$} \\
\hline & & & & & & & & & \\
\hline & & & & & & & & & \\
\hline \multicolumn{10}{|l|}{ Age (years) } \\
\hline $20-39$ & $9.3(8.5-10.1)$ & 0.4 & $9.9(7.6-12.1)$ & 1.1 & $9.3(8.1-10.4)$ & 0.6 & $7.8(6.8-10.1)$ & 0.6 & 0.03 \\
\hline $40-59$ & $39.4(37.8-41.0)$ & 0.8 & $40.7(38.0-43.4)$ & 1.4 & $39.4(36.7-42.1)$ & 1.4 & $39.7(35.8-41.3)$ & 1.4 & 0.06 \\
\hline$\geq 60$ & $51.2(49.5-52.9)$ & 0.9 & $49.3(45.9-52.7)$ & 1.7 & $51.2(48.3-54.1)$ & 1.5 & $52.4(49.7-55.0)$ & 1.3 & $<0.01$ \\
\hline Female & $48.8(47.2-50.3)$ & 0.8 & $49.0(46.7-51.2)$ & 1.1 & $49.5(46.7-52.3)$ & 1.4 & $48.1(45.5-50.7)$ & 1.3 & 0.57 \\
\hline \multicolumn{10}{|l|}{ Educational Status } \\
\hline$<$ High school & $27.7(26.1-29.2)$ & 0.8 & $34.2(27.4-36.9)$ & 1.4 & $27.3(22.1-30.4)$ & 1.1 & $23.0(20.9-25.4)$ & 1.4 & $<0.001$ \\
\hline High school graduate & $24.7(23.1-26.3)$ & 0.8 & $25.3(22.4-28.1)$ & 1.4 & $26.2(23.0-29.3)$ & 1.6 & $23.3(20.9-25.4)$ & 1.2 & 0.19 \\
\hline Some college & $29.2(27.5-30.8)$ & 0.8 & $25.8(22.9-28.6)$ & 1.5 & $28.8(25.0-30.7)$ & 1.4 & $32.4(29.8-34.9)$ & 1.3 & $<0.001$ \\
\hline College education or above & $18.3(16.7-19.9)$ & 0.8 & $14.6(12.3-17.0)$ & 1.2 & $17.7(15.1-20.0)$ & 1.2 & $21.3(18.1-24.2)$ & 1.5 & $<0.001$ \\
\hline \multicolumn{10}{|l|}{ Poverty-to-income ratio } \\
\hline$<100 \%$ & $17.2(15.8-18.7)$ & 0.8 & $17.3(14.7-19.9)$ & 1.3 & $14.6(12.2-16.6)$ & 1.1 & $19.6(16.9-22.2)$ & 1.4 & 0.08 \\
\hline $100-299 \%$ & $42.9(41.1-44.6)$ & 0.9 & $44.9(41.2-48.5)$ & 1.8 & $44.5(42.1-47.6)$ & 1.4 & $39.9(37.1-42.8)$ & 1.4 & 0.04 \\
\hline $300-499 \%$ & $22.2(15.8-18.7)$ & 0.8 & $22.0(19.3-24.6)$ & 1.3 & $21.2(18.6-23.5)$ & 1.2 & $23.3(20.3-26.1)$ & 1.5 & 0.33 \\
\hline$\geq 500 \%$ & $17.6(15.9-19.3)$ & 0.9 & $15.7(12.6-18.8)$ & 1.6 & $19.6(17.3-21.9)$ & 1.2 & $17.1(14.0-20.3)$ & 1.6 & 0.57 \\
\hline \multicolumn{10}{|l|}{ Race and ethnicity } \\
\hline Whites & $61.0(57.9-64.1)$ & 1.6 & $63.8(58.4-68.9)$ & 2.7 & $62.5(57.0-67.8)$ & 2.7 & $58.2(53.0-63.4)$ & 2.6 & 0.01 \\
\hline Blacks & $15.9(14.0-17.5)$ & 1.0 & $15.3(12.0-18.5)$ & 1.7 & $16.8(13.8-17.6)$ & 1.5 & $15.6(12.2-18.8)$ & 1.7 & 0.98 \\
\hline Hispanics & $15.1(12.7-17.5)$ & 1.2 & $13.9(9.1-18.9)$ & 2.5 & $14.0(10.4-17.6)$ & 1.8 & $16.6(12.6-20.5)$ & 2.0 & $<0.001$ \\
\hline Others & $7.9(6.7-9.0)$ & 0.6 & $6.9(4.6-9.1)$ & 1.2 & $6.6(4.9-8.3)$ & 0.9 & $9.5(7.6-11.5)$ & 1.0 & 0.06 \\
\hline Insured & $87.8(86.8-88.8)$ & 0.5 & $87.9(86.1-89.8)$ & 0.9 & $87.3(85.3-89.2)$ & 1.0 & $88.2(86.8-89.6)$ & 0.7 & 0.73 \\
\hline \multicolumn{10}{|l|}{ BMI, kg/m² } \\
\hline$<25$ & $12.7(11.5-13.9)$ & 0.6 & $15.0(12.0-18.1)$ & 1.5 & $12.8(11.2-14.4)$ & 0.8 & $11.7(9.5-13.0)$ & 0.9 & 0.02 \\
\hline $25-<30$ & $26.7(25.3-28.1)$ & 0.7 & $30.1(27.0-33.2)$ & 1.6 & $25.6(23.2-28.1)$ & 1.2 & $26.1(23.5-27.8)$ & 1.1 & 0.14 \\
\hline$\geq 30$ & $60.5(58.6-62.4)$ & 1.0 & $54.8(50.6-58.8)$ & 2.1 & $61.5(58.5-64.4)$ & 1.5 & $62.1(59.9-66.0)$ & 1.5 & $<0.01$ \\
\hline Current smoker & $17.1(16.0-18.1)$ & 0.5 & $19.7(17.6-21.8)$ & 1.1 & $17.0(15.3-18.7)$ & 0.9 & $15.5(13.9-17.2)$ & 0.9 & $<0.01$ \\
\hline Statin user & $57.6(55.9-59.4)$ & 0.9 & $28.4(25.3-31.5)$ & 1.0 & $46.3(44.1-48.5)$ & 1.1 & $50.1(46.6-53.7)$ & 1.8 & $<0.001$ \\
\hline \multicolumn{10}{|l|}{ Diabetes medication } \\
\hline Oral medications & $55.0(53.2-56.9)$ & 0.8 & $55.8(52.3-59.2)$ & 1.2 & $56.8(51.4-58.4)$ & 1.5 & $57.9(52.1-60.1)$ & 1.3 & 0.001 \\
\hline Insulin & $13.2(11.7-14.1)$ & 0.5 & $15.8(12.8-18.9)$ & 1.3 & $12.9(10.9-14.8)$ & 0.8 & $11.5(9.8-13.1)$ & 0.8 & 0.01 \\
\hline Oral medications and insulin & $12.5(11.4-13.6)$ & 0.5 & $10.4(7.6-13.0)$ & 1.1 & $10.7(11.9-15.4)$ & 0.7 & $10.5(11.1-14.1)$ & 0.8 & 0.21 \\
\hline HbA1c $<8 \%$ & $75.3(74.1-77.0)$ & 0.8 & $72.1(70.2-75.4)$ & 1.3 & $73.6(72.0-77.3)$ & 1.3 & $79.6(77.8-81.4)$ & 1.3 & $<0.001$ \\
\hline \multicolumn{10}{|l|}{ Blood pressure control } \\
\hline$<140 / 90 \mathrm{~mm} \mathrm{Hg}$ & $71.5(69.9-73.0)$ & 0.8 & $67.4(64.7-70.1)$ & 1.4 & $71.8(69.5-74.1)$ & 1.2 & $73.6(70.9-76.4)$ & 1.4 & 0.01 \\
\hline$<130 / 80 \mathrm{~mm} \mathrm{Hg}$ & $48.6(46.8-50.3)$ & 0.8 & $42.3(38.6-46.1)$ & 1.8 & $50.2(47.5-53.0)$ & 1.3 & $51.1(48.4-53.7)$ & 1.4 & 0.03 \\
\hline \multicolumn{10}{|l|}{ Lipid profile } \\
\hline $\mathrm{LDL}-\mathrm{C} \leq 100 \mathrm{mg} / \mathrm{dL}$ & $46.6(44.0-49.2)$ & 1.3 & $35.0(30.1-40.0)$ & 2.5 & $50.6(46.7-54.6)$ & 2.0 & $51.4(47.0-55.8)$ & 2.2 & $<0.001$ \\
\hline Triglycerides $\leq 150 \mathrm{mg} / \mathrm{dL}$ & $53.2(50.3-56.2)$ & 1.5 & $44.3(39.9-48.6)$ & 2.2 & $54.5(50.5-58.5)$ & 2.0 & $58.4(51.4-65.5)$ & 2.5 & $<0.001$ \\
\hline \multicolumn{10}{|c|}{ Health services use in the past year } \\
\hline Foot exam & $71.5(69.4-73.7)$ & 1.1 & $*$ & $*$ & $71.4(68.7-74.0)$ & 1.3 & $71.8(68.5-75.0)$ & 1.6 & 0.35 \\
\hline Eye exam & $63.8(61.1-65.8)$ & 1.2 & $*$ & $*$ & $63.7(60.5-66.9)$ & 1.6 & $63.0(59.6-66.5)$ & 1.7 & 0.76 \\
\hline Visited diabetes educator & $36.9(34.9-39.0)$ & 1.0 & $*$ & $*$ & $38.5(35.3-41.7)$ & 1.6 & $34.8(32.4-37.1)$ & 1.2 & 0.06 \\
\hline Comorbidities & & & & & & & & & \\
\hline Hypertension & $64.8(63.1-66.5)$ & 0.8 & $61.3(58.3-64.4)$ & 1.5 & $65.8(62.9-68.6)$ & 1.5 & $65.9(63.2-68.7)$ & 1.4 & $<0.001$ \\
\hline Chronic kidney disease & $22.4(21.3-23.5)$ & 0.6 & $21.6(19.5-23.7)$ & 1.1 & $22.3(20.3-24.3)$ & 1.0 & $22.9(21.2-24.6)$ & 0.9 & 0.01 \\
\hline Cardiovascular diseases & $23.3(21.9-24.7)$ & 0.7 & $23.7(20.4-27.1)$ & 1.7 & $23.9(21.7-26.1)$ & 1.1 & $22.6(20.7-24.4)$ & 0.9 & 0.47 \\
\hline Albuminuria & $27.3(25.9-28.7)$ & 0.7 & $30.9(28.8-33.1)$ & 1.1 & $27.0(25.0-29.1)$ & 1.0 & $25.4(22.7-28.0)$ & 1.3 & $<0.01$ \\
\hline
\end{tabular}

